\title{
Experimental and theoretical investigations on the inhibition efficiency of $N$-(2,4-dihydroxytolueneylidene)-4-methylpyridin-2- amine for the corrosion of mild steel in hydrochloric acid
}

\author{
Y.M. Abdulsahib, ${ }^{1}$ A.J.M. Eltmimi, ${ }^{2}$ S.A. Alhabeeb, ${ }^{3}$ M.M. Hanoon, ${ }^{1}$ \\ A.A. Al-Amiery, ${ }^{4,5}$ (D) T. Allami ${ }^{5}$ and A.A.H. Kadhum ${ }^{5}$ \\ ${ }^{1}$ Production Engineering and Metallurgy, University of Technology, P.O. Box: 10001, \\ Baghdad, Iraq \\ ${ }^{2}$ Al-Esraa University College (EUC) P.O. Box: 10001, Baghdad, Iraq \\ ${ }^{3}$ College of engineering, University of Warith Al-Anbiyaa, Karbala, Iraq \\ ${ }^{4}$ Energy and renewable energies technology center, University of Technology, Baghdad, \\ 10001 Iraq \\ ${ }^{5}$ Department of Chemical and Process Engineering, University Kebangsaan Malaysia \\ (UKM), P.O. Box: 43000, Bangi, Selangor, Malaysia \\ *E-mail:dr.ahmed1975@ukm.edu.my,dr.ahmed197@gmail.com
}

\section{Abstract}

Low carbon steel is an important construction material utilized in various industries mostly for its outstanding mechanical characteristics and its rather low cost compared to other materials. The current investigation studies the ability of $\mathrm{N}$-(2,4-dihydroxytolueneylidene)-4methylpyridin-2-amine (N-MDA), a Schiff base, on low-carbon steel corrosion inhibition in $1 \mathrm{M} \mathrm{HCl}$ environment utilizing weight loss techniques under the effect of different methodological restrictions. Experimental findings showed that (N-MDA) is an efficient inhibitor and inhibitive efficacy increased with increasing N-MDA concentration; reaching the highest rate of $93.7 \%$ at a N-MDA concentration of $0.0005 \mathrm{M}$. The effect of temperature of $\mathrm{N}$ (2,4-dihydroxytolueneylidene)-4-methylpyridin-2-amine on the corrosion of low carbon steel in $1 \mathrm{M} \mathrm{HCl}$ solution was also investigated by weight loss experiments at temperatures ranging from 303 to $333 \mathrm{~K}$. The adsorption of the N-MDA molecules on the low-carbon steel surface followed the Langmuir isotherm model with the adsorption free energy $\left(\Delta G_{\text {ads }}^{0}\right)$ of $-38.9 \mathrm{~kJ} \cdot \mathrm{mol}^{-1}$. Density function theory (DFT) has been used to perform quantitative calculations to correlate the structural and electronic properties of the investigated N-MDA molecules with the evaluation of the inhibitory activity. Electronic factors such as the Highest Occupied Molecular Orbital (HOMO), the Lowest Unoccupied Molecular Orbital (LUMO), the energy gap $(\Delta E)$, hardness, softness and electronegativity were calculated and discussed. The conclusions reached from the weight loss measurements and quantum chemical calculations are in good agreement.

Received: June 2, 2021. Published: July 7, 2021.

doi: $\underline{10.17675 / 2305-6894-2021-10-3-3}$

Keywords: weight loss, density function theory, low-carbon steel, corrosion inhibition. 


\section{Introduction}

In general, corrosion inhibitors have been extensively investigated in various applications to reduce the corrosion rate of alloy surfaces in corrosive solutions [1-3]. Corrosive environments are commonly used in various industrial processes, such as pickling, acid cleaning, acid descaling, acidification, oil and gas operations, etc. [4]. Among acidic environments, hydrochloric acid is used most commonly for acidification and for this reason the main focus is on this acid. The application of corrosion inhibitors is one of the various effective techniques for the protection of low-carbon steel versus corrosion, particularly in hydrochloric acid environments to prevent steel decay and damage [5]. Low-carbon steel in a hydrochloric acid environment is extensively utilized in different manufacturers and lowcarbon steel corrosion is known to happen in this solution. Generally, the most efficient technique to inhibit corrosion is the usage of natural/synthesized organic inhibitor molecules [6]. Several scientific techniques have been applied to address the corrosion problem of low carbon steels in corrosive solutions [7]. The most effective natural inhibitors utilized have heteroatoms such as phosphorous, sulfur, oxygen, and nitrogen in addition to double and triple bonds in the molecular structure of tested inhibitors through which these inhibitors are adsorbed on the surface of tested alloy $[8,9]$. It can be noted that adsorption processes depend essentially on specific physicochemical characteristics of the structural molecular composition of inhibitor molecules including the active sites, electron density, pi-bonds, and the electronic system [10]. Laboratory routines are extremely useful in the understanding of the mechanism of corrosion inhibition however experimental techniques are commonly costly. With the growth of computer performance and programming, DFT (density functional theory) $[11,12]$ quantum chemical calculation techniques have become active and important instruments in the past years for understanding the inhibition mechanism and predict inhibition efficiency of organic inhibitors [13-18]. The quantum factors including hardness [19, 20], softness [21], electronegativity [22], proton affinity [23], electrophilicity [24] and nucleophilicity are granted in the understanding of stability. Koopmans Theorem [25] gives excellent abilities to chemical or physical programmer. Based on Koopmans Theorem theory, the values of ionization potential and electron affinity of organic molecules are connected with energy values of frontier molecular orbitals (MOs) which are named the HOMO and the LUMO (HOMO is Highest Occupied MO, the highest-energy MO that has electrons in it. LUMO is Lowest Unoccupied MO, the lowest-energy MO that doesn't have any electrons in it. Frontier MOs are very important for reactivity). The purpose of the current research is to assess the inhibition efficiency of a new corrosion inhibitor namely " $\mathrm{N}$ (2,4-dihydroxytolueneylidene)-4-methylpyridin-2-amine (N-MDA)" on the low-carbon steel in $1 \mathrm{M}$ hydrochloric acid environment. The corrosive inhibitive achievement was investigated utilizing weight loss techniques. The effects of concentrations, temperature, and exposure time on the corrosion inhibition of low-carbon steel in $1 \mathrm{M} \mathrm{HCl}$ solution was studied also. Thus, N-MDA is a nitrogen and oxygen-containing molecule and excellent donor of electrons that improves the process of adsorption on the low-carbon surface and 
increases the required abilities. The chemical molecular structure of N-MDA molecule examined in this investigation is presented in Figure 1.

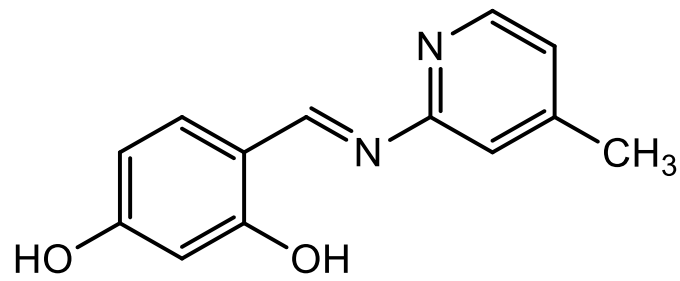

Figure 1. The chemical structure of N-MDA molecule.

\section{Experimental}

\subsection{Materials and Material Preparation}

The chemical composition of the low-carbon steel used to make the specimens (Metal Samples Company) is presented in Table 1.

Table 1. Elemental analysis for low-carbon steel.

\begin{tabular}{cccccccc}
\hline Elements & Carbon & Phosphorus & Manganese & Silicon & Aluminum & Sulfur & Iron \\
\hline Composition & $0.21 \%$ & $0.09 \%$ & $0.05 \%$ & $0.038 \%$ & $0.01 \%$ & $0.050 \%$ & Balance $\%$
\end{tabular}

Low carbon steel samples with the measurements $(2.0 \times 1.0 \times 0.05 \mathrm{~cm})$ were cut from low-carbon steel strips. Specimens were polished utilizing silicon carbide emery papers, soaked in ethyl alcohol, then degreased with acetone, ethyl alcohol, and subsequently with deionized water. Eventually, they were dried utilizing an oven. The $\mathrm{HCl}$ environment with a concentration of $1 \mathrm{M}$ was prepared by dilution of $37 \%$ hydrochloric acid analytical grades utilizing deionized water.

\subsection{Weight loss techniques}

Gravimetric techniques have been conducted based on the ASTM G31-72 standard method [26]. The specimens were soaked in $1.0 \mathrm{M} \mathrm{HCl}$ medium in the absence and presence of various concentrations $(0.0001,0.0002,0.0003,0.0004$, and $0.0005 \mathrm{M})$ of tested inhibitor for $1,5,10$, and $24 \mathrm{~h}$ at $303 \mathrm{~K}$. Following that, the specimens were taken out, fully soaked in distilled water and ethyl alcohol, and next dried in the oven following the corrosion experiments. The loss in mass was evaluated utilizing an electrical balance and measurements were conducted triplicate. Moreover, the mean value was accepted in estimations. The measurements were also conducted medium in the absence and presence of various concentrations of tested inhibitor for $5 \mathrm{~h}$ at $303,313,323$, and $333 \mathrm{~K}$. 


\subsection{Density Function Theory (DFT) calculations}

DFT calculations have been conducted applying DFT techniques, using the current Becke's three-parameter hybrid functional (B3LYP) theory level with the basis set 6-31 G through the Gaussian 03 programs series. The associated DFT chemical factors were evaluated and studied.

\section{Results and discussion}

\subsection{Chemistry of the inhibitor}

Schiff bases are traditionally prepared by the condensation reaction of a primary amine (4methylpyridin-2-amine) and an aldehyde (2,4-dihydroxybenzaldehyde) which involves the use of ethanol as an organic solvent (Figure 2).
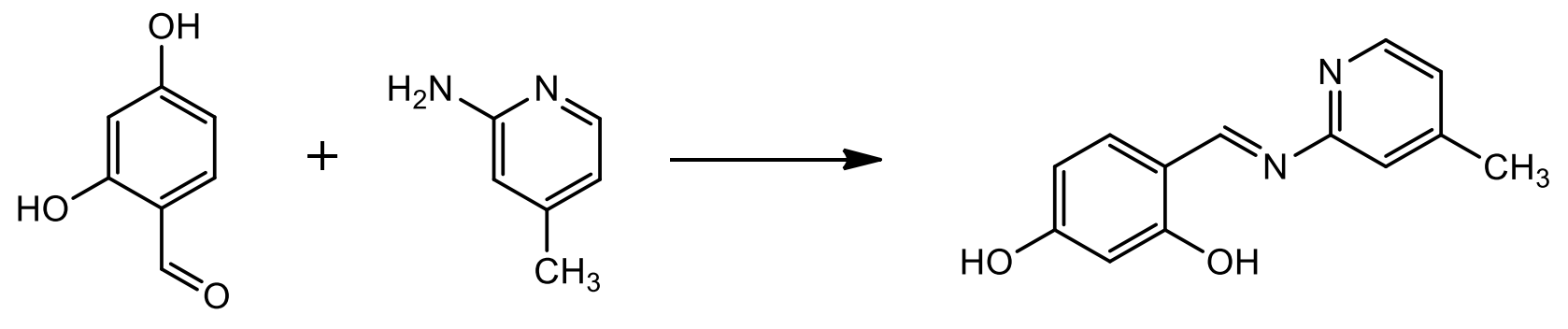

Figure 2. The synthetic pathway to N-MDA molecule.

\subsection{Weight loss techniques: Effect of concentration}

The corrosion rate $\left(C_{\mathrm{R}}\right)$ and inhibition efficiency $(I E \%)$ derived from the weight loss analyses in the absence and presence of various concentrations of N-MDA for low-carbon steel in $1.0 \mathrm{M} \mathrm{HCl}$ are demonstrated in Figure $3 . C_{\mathrm{R}}$ and $I E \%$ were calculated according to ASTM G31-72 standard, utilizing the equations (1 and 2) at various immersion time:

$$
\begin{gathered}
C_{\mathrm{R}}=\frac{87600 W}{S T D} \\
I E \%=\frac{C_{\mathrm{R}}^{0}-C_{\mathrm{R}}}{C_{\mathrm{R}}^{0}} \cdot 100
\end{gathered}
$$

where $W$ is the specimen weight loss $(\mathrm{g}), S$ is the surface area $\left(\mathrm{cm}^{2}\right), T$ represent the exposure period (h), $D$ refers to the low-carbon steel density $\left(\mathrm{g} \cdot \mathrm{cm}^{-3}\right), C_{\mathrm{R}}$ is the corrosion rate in the absence of the tested inhibitor, and $C_{\mathrm{R}}^{0}$ represents the corrosion rate in the presence of the tested inhibitor. 

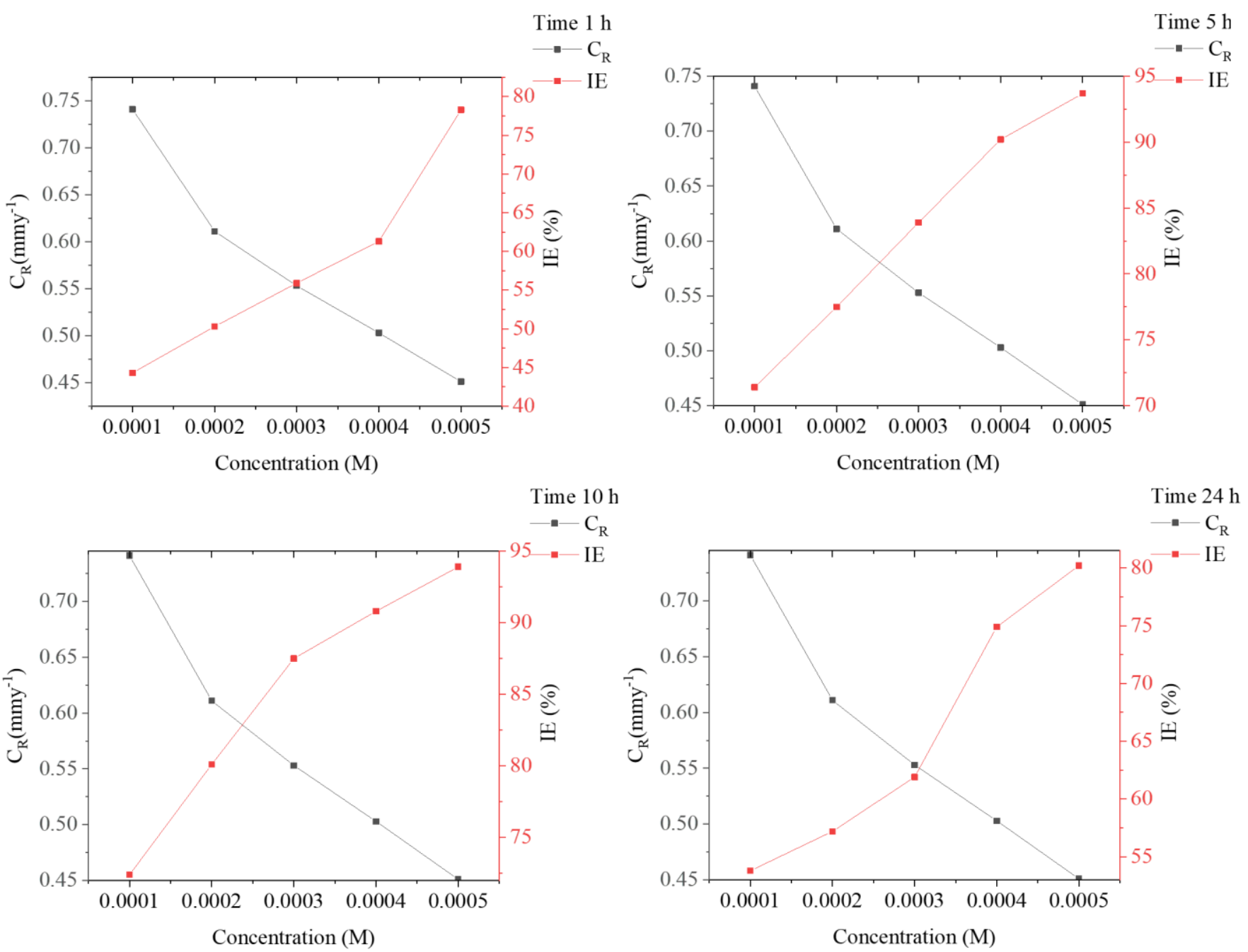

Figure 3. Weight loss effects of low-carbon steel in $1.0 \mathrm{M} \mathrm{HCl}$ with various concentrations of $\mathrm{N}-\mathrm{MDA}$ at various immersing time.

From Figure 3, it is obvious that the rate of corrosion of low-carbon steel reduced significantly and the corrosion inhibition efficacy increased with the increase in the concentration of N-MDA. The increase in inhibition efficacy can be imputed to the increase in surface coverage due to the inhibitor molecules' adsorption on the surface of low-carbon steel [27]. Then, the adsorption layer may prevent the active sites and separate the lowcarbon steel surface from the corrosive environment. In order to compare the recent investigations on Schiff bases as corrosion inhibitors, N-MDA showed more excellent inhibition performance as presented in Table 2. This event is linked to the presence of nitrogen and oxygen atoms, heterocyclic and benzene rings, and resonance effect on the whole inhibitor molecules in addition to the low effect of steric hindrance. 
Table 2. Comparison of the inhibitive efficacy of N-MDA with the reported data as inhibitors for alloy in corrosive environment.

\begin{tabular}{|c|c|c|c|}
\hline Inhibitor & Concentration & $\begin{array}{l}\text { Inhibition } \\
\text { Efficiency }\end{array}$ & Reference \\
\hline N-MDA & $0.0005 \mathrm{M}$ & 93.7 & Current study \\
\hline $\mathrm{N}$-(4-(dimethylamino)benzylidene)benzothiazol-2-amine & $10 \mathrm{mmol} / \mathrm{L}$ & 88.8 & {$[28]$} \\
\hline $\mathrm{N}$-(4-(dimethylamino)benzyl)benzothiazole-2-amine & $10 \mathrm{mmol} / \mathrm{L}$ & 96.7 & {$[28]$} \\
\hline $\begin{array}{c}\text { 4,4'-((((Ethane-1,2-diylbis(oxy))bis(4,1- } \\
\text { phenylene) }) \text { bis(methaneylylidene) }) \text { bis(azaneylylidene })) \text { - } \\
\text { bisferrocene }\end{array}$ & $100 \mathrm{ppm}$ & 88.00 & {$[29]$} \\
\hline $\begin{array}{c}\text { 4,4'-((((Ethane-1,2-diylbis(oxy))bis(2-methoxy-1,4- } \\
\text { phenylene))bis(methaneylylidene))bis(azaneylylidene })) \text { - } \\
\text { bisferrocene }\end{array}$ & $100 \mathrm{ppm}$ & 92.00 & {$[29]$} \\
\hline $\begin{array}{c}\text { 4,4'-((((Ethane-1,2-diylbis(oxy))bis(2-ethoxy-1,4- } \\
\text { phenylene))bis(methaneylylidene))bis(azaneylylidene))- } \\
\text { bisferrocene }\end{array}$ & $100 \mathrm{ppm}$ & 97.60 & {$[29]$} \\
\hline $\begin{array}{c}N \text {-[(Z)-1-Phenylemethyleidene }]-N-\{2-[(2-\{[(Z)-1- \\
\text { phenylmethylidene }] \text { amino }\} \text { phenyl }) \text { disulfanyl }] \text { phenyl }\} \\
\text { amine }\end{array}$ & $1 \mathrm{M}$ & 96.1 & {$[30]$} \\
\hline 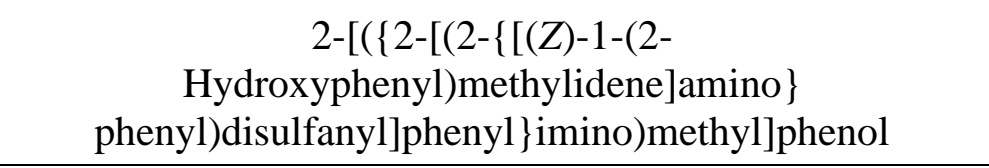 & $1 \mathrm{M}$ & 93.5 & {$[30]$} \\
\hline $\begin{array}{c}N-[(Z)-1-(4-\text { Methylphenyl)methylidene }]-N-\{2-[(2-\{[(Z)- \\
1-(4 \text { methylphenyl)methylidene }] \text { amino }\} \text { phenyl }) \text { disulfanyl }] \\
\text { phenyl }\} \text { amine }\end{array}$ & $1 \mathrm{M}$ & 94.1 & {$[30]$} \\
\hline $\begin{array}{c}\text { Benzyl 2-(1-(5-methyl-1-(p-tolyl)-1H-1,2,3-triazole-4- } \\
\text { yl)-ethylidene) hydrazine-1-carbodithioate }\end{array}$ & $0.5 \mathrm{mM}$ & 93.4 & {$[31]$} \\
\hline $\begin{array}{c}\text { Methyl 2-(1-(5-methyl-1-( } p \text {-tolyl)-1H-1,2,3-triazol-4- } \\
\text { yl)ethylidene)hydrazinecarbodithioate }\end{array}$ & $0.5 \mathrm{mM}$ & 95.1 & {$[32]$} \\
\hline $\begin{array}{l}\text { 2-((6-Methyl-2-ketoquinoline-3-yl)methylene) } \\
\text { hydrazinecarbothioamide }\end{array}$ & $0.005 \mathrm{M}$ & 95.84 & {$[33]$} \\
\hline 1-Phenyl-2-(1-phenylethylidene)hydrazine & $0.005 \mathrm{M}$ & 83.8 & {$[34]$} \\
\hline 1-(1-(4-Methoxyphenyl)ethylidene)-2-phenylhydrazine & $0.005 \mathrm{M}$ & 95.1 & {$[34]$} \\
\hline $\begin{array}{c}\text { 2-(2,4-Dimethoxybenzylidene)- } N \text { - } \\
\text { phenylhydrazinecarbothioamide }\end{array}$ & $0.005 \mathrm{M}$ & 94.8 & {$[35]$} \\
\hline 5-((4-Fluorobenzylidene)amino)-1,3,4-thiadiazole-2-thiol & $0.5 \mathrm{mM}$ & 91 & {$[36]$} \\
\hline $\begin{array}{l}N^{\prime} \text {-(1-phenylethylidene)-4-(1H-pyrrol-1- } \\
\text { yl)benzohydrazide }\end{array}$ & $500 \mathrm{ppm}$ & 94.5 & {$[37]$} \\
\hline
\end{tabular}




\subsection{Weight loss techniques: Effect of temperature}

Generally, the temperature effect on the inhibited acid-steel reaction was extremely difficult to determine due to various differences that happened on the alloy surface, including accelerated etching and desorption of inhibitor molecules. Moreover, to improve adsorption efficiency, the inhibitor may undergo hydrolysis, rearrangement, or chemical modifications [38]. To examine the impact of temperature on the inhibitive effect of the studied N-MDA inhibitor, gravimetric measurements were conducted at various temperatures $(303-333 \mathrm{~K})$ as described in Figure 4. The inhibition efficiency, on the other hand, remained nearly unchanged, which may be imputed to chemical alterations in the tested inhibitor molecules. From the above, it can be said that N-MDA showed great inhibitory efficiency at different temperatures.
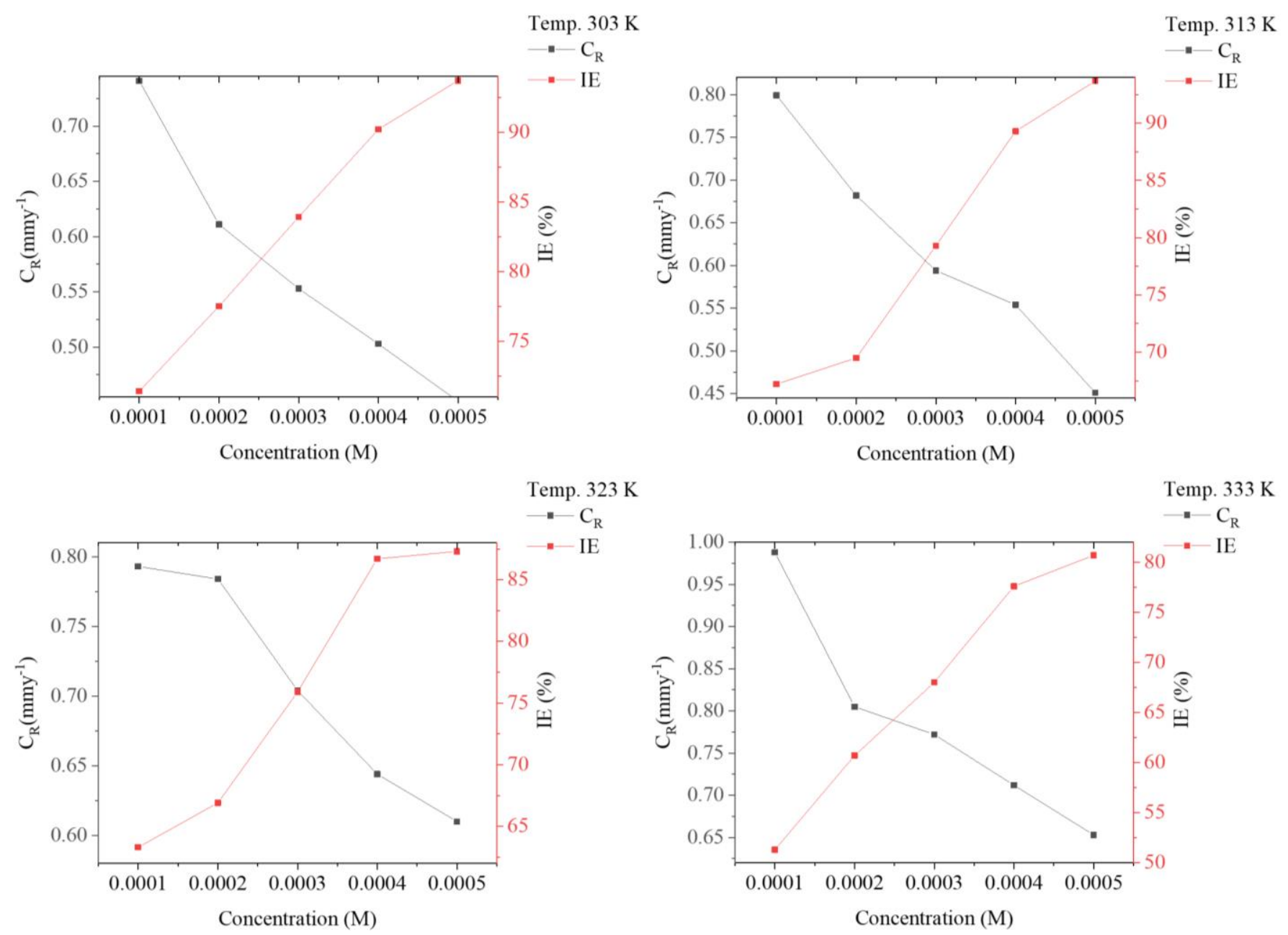

Figure 4. Weight loss effects of low-carbon steel in $1.0 \mathrm{M} \mathrm{HCl}$ with various concentrations of $\mathrm{N}-\mathrm{MDA}$ at various temperatures for $5 \mathrm{~h}$ exposure time.

\subsection{Adsorption isotherm}

The competitive process of adsorption that occurs at the inhibitor/solution interface (electrode/electrolyte) is controlled by a semi-substitution process. Various adsorption 
isotherm types including Temkin, Langmuir and Frumkin are applied to fit the relationship between the concentration of tested inhibitor $\left(C_{\text {inh }}\right)$ and the surface coverage $(\theta)$. According to the high correlation coefficient $\left(R^{2}\right)$, the most fitted one obeyed the Langmuir isotherm as presented in Figure 5, which represents the process of adsorption faultlessly as per in Equation $3[39,40]$.

$$
\frac{C}{\theta}=\frac{1}{K_{\mathrm{ads}}}+C
$$

where $\theta$ refers to the surface coverage, $K_{\text {ads }}$ represents the adsorption constant, and $C$ is the concentration of the tested inhibitor.

The free adsorption energy $\left(\Delta G_{\text {ads }}\right)$ of inhibitor molecules was determined from the adsorption constant $\left(K_{\text {ads }}\right)$ value as per in Equation 4,

$$
\Delta G_{\mathrm{ads}}=\left(\frac{1}{55.5}\right) \exp \left(\frac{-K_{\mathrm{ads}}}{R T}\right)
$$

where the value 55.5 is the water molar concentration (M), $T$ is the temperature and $R$ is the universal gas constant.

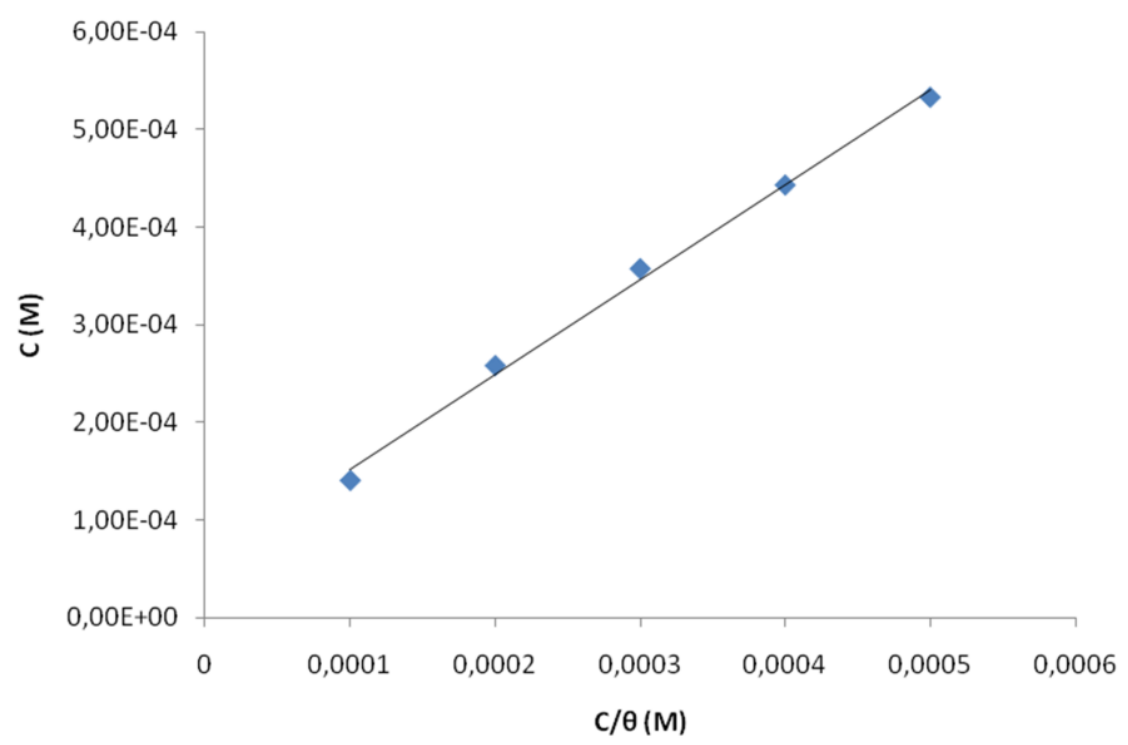

Figure 5. Langmuir adsorption isotherm of N-MDA on low-carbon steel surface in $1 \mathrm{M} \mathrm{HCl}$ at $303 \mathrm{~K}$.

The $\Delta G_{\text {ads }}$ value is calculated and it was equal to $-38.9 \mathrm{~kJ} \cdot \mathrm{mol}^{-1}$. The $K_{\text {ads }}$ with significant value shows the power of adsorption of the tested inhibitor molecules, and $\Delta G_{\text {ads }}$ with negative symbol value refers to that the process of adsorption is spontaneity. The $\Delta G_{\text {ads }}$ with a high-value point to that the chemisorption process, which is done when the electron pairs transfer from high inhibitor molecules active sites to the unoccupied $d$-orbital of iron atoms on the surface of low-carbon steel, producing coordination bonds. 


\subsection{DFT calculations}

The inhibition efficiency is affected by the electronic characteristics and the structure of the inhibitor molecules. In the $\mathrm{HCl}$ solution, the investigated inhibitor molecules could exist in the equilibrium form of protonated and non-protonated (N-MDA). In aforementioned opinion, the HOMO and LUMO distributions of non-protonated N-MDA were studied, as demonstrated in Figure 6. The quantum characteristics are presented in Table 3.

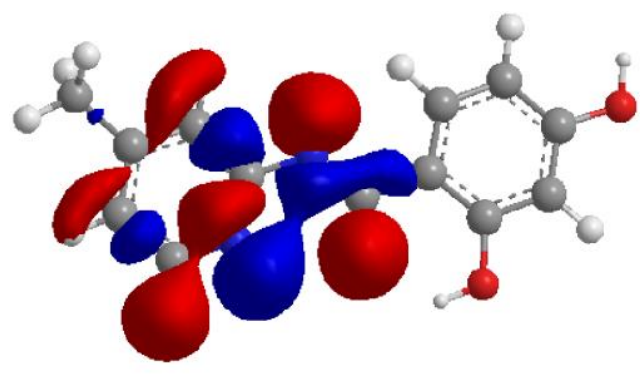

HOMO -9.823

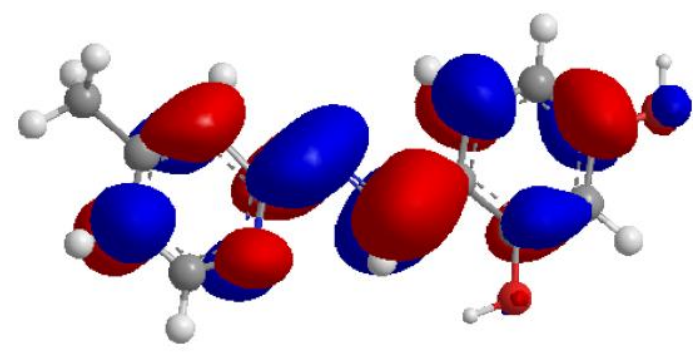

LUMO - 4.453

Figure 6. HOMO and LUMO distributions of the non-protonated N-MDA.

Table 3. Quantum chemical characteristics for tested inhibitor molecules.

\begin{tabular}{ccccc}
\hline Inhibitor & $\boldsymbol{E}_{\text {номо }}(\mathbf{e V})$ & $\boldsymbol{E}_{\text {LUMо }}(\mathbf{e V})$ & $\boldsymbol{\mu}(\mathrm{D})$ & $\Delta N_{110}(\mathbf{e})$ \\
\hline N-MDA & -9.823 & -4.453 & 3.11 & 0.17 \\
\hline
\end{tabular}

Based on DFT calculations, molecular reactivity can be investigated through the study the HOMO stands for "Highest Occupied Molecular Orbital", and LUMO stands for "Lowest Unoccupied Molecular Orbital" distributions. The energy of HOMO represents the ability of electron-donating of an inhibitor molecule, whereas the energy of LUMO indicates the ability of electron-accepting of an inhibitor molecule [41]. From Figure 6, it can be noticed that the Highest Occupied Molecular Orbital distribution is distributed mainly over the heterocyclic ring and isomethine which represent the structure of the isomethine in the inhibitor molecules, whereas the Lowest Unoccupied Molecular Orbital is chiefly spread on the whole molecule. Therefore, the isomethine group and heterocyclic ring section are the general adsorption center which functions as the principal sites for giving electrons to the empty $d$-orbital of the Fe atoms on the surface of low-carbon steel to form coordination bond. Furthermore, the entire inhibitor molecule can receive electrons from the Fe-atom with its anti-bonding orbitals to form another kind of bonds via a feedback mechanism. The dipole moment $(\mu)$ is a different significant electronic factor reflected in corrosion investigations. The value of dipole moment of the studied inhibitor was 3.11 as in Table 3 , and the low value of dipole moment choosing a significant increase of inhibitor molecules on the surface of low-carbon steel [42]. Besides the assistant of the finite variation technique, the electronegativity $(\chi)$ and hardness $(\gamma)$ can be approximated according to the potential of ionization $(I)$ and electron affinity $(A)$ [43]. Regarding Koopman's theorem [25], the values 
of ionization potential and electron affinity are determined as $I=-$ the energy of HOMO and $A=-$ the energy of LUMO. Hence, electronegativity $(\chi)$ and hardness $(\gamma)$ can be evaluated according to the relations $\chi=-0.5(\mathrm{HOMO}+\mathrm{LUMO})$ and $\gamma=0.5(-\mathrm{HOMO}+\mathrm{LUMO})$. The metal surface work function $(\Phi)$ is a suitable analysis technique of the $\Delta N$ (fraction of electrons) and electronegativity. $\Delta N$ can be evaluated according to the Equation 5:

$$
\Delta N=\frac{\Phi-\chi_{\text {inh }}}{2\left(\gamma_{\mathrm{Fe}}+\gamma_{\mathrm{inh}}\right)}
$$

where $\chi_{\text {inh }}, \gamma_{\mathrm{Fe}}\left(\gamma_{\mathrm{Fe}} \approx 0 \mathrm{eV}\right)$ and $\gamma_{\text {inh }}$ refer to the electronegativity of the inhibitor, and the hardness of iron and the inhibitor molecule, respectively. If the $\Delta N$ value $>0$, it clearly suggests that the transfer of electrons occurs from the inhibitor onto the metal surface. In the current investigation, it was obvious that the $\Delta N$ value was positive for the interactions of tested inhibitor molecules with iron atoms on the surface of low-carbon steel. Hence, the tested inhibitor molecules behave as if they were an electron donor, supporting an absorption layer on the surface of the low carbon steel. From above theoretical conclusions herein we can postulate a mechanism of action between N-MDA molecules and metal surface as in Figure 7.

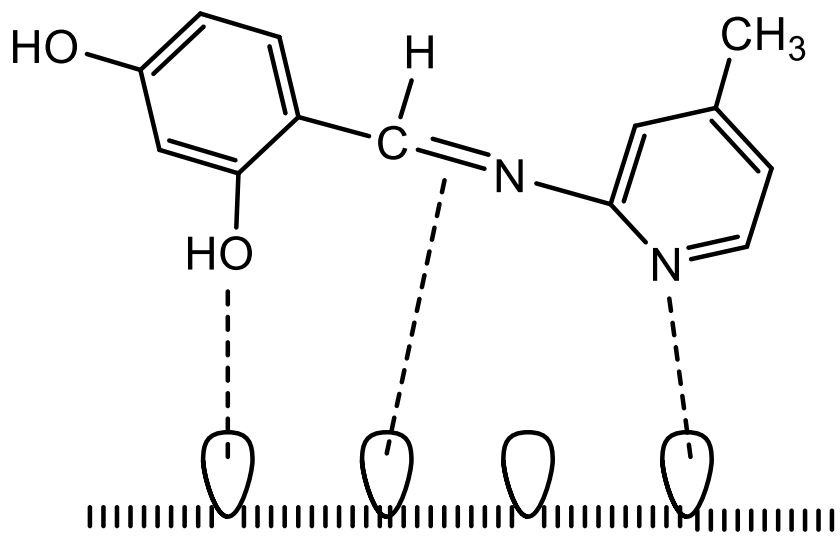

Figure 7. The suggested inhibition mechanism.

\section{Conclusions}

New Schiff base inhibitor, namely $N$-(2,4-dihydroxytolueneylidene)-4-methylpyridin-2amine (N-MDA), was synthesized and investigated for its corrosive inhibitive characteristics on low-carbon steel in 1.0 M hydrochloric acid solution. The following conclusions were drawn from the experimental and DFT results obtained:

1. N-MDA shows excellent inhibitory properties toward low carbon steel in a corrosive environment, and the demonstrated inhibitory effectiveness is $93.7 \%$.

2. The corrosive inhibitive performance of the tested inhibitor increases significantly with increasing concentration and decreases with increasing temperature.

3. The adsorption of N-MDA follows the Langmuir isotherm. 
4. The significant inhibition efficacy of the synthesized inhibitor was confirmed by the experimental findings and DFT calculations. The experimental and theoretical data are in good agreement.

\section{Conflicts of interest}

There are no conflicts to declare.

\section{References}

1. M. Christov and A. Popova, Adsorption characteristics of corrosion inhibitors from corrosion rate measurements, Corros. Sci., 2004, 46, no. 7, 1613-1620. doi: 10.1016/S0010-938X(03)00284-1

2. P.C. Okafor, X. Liu and Y.G. Zheng, Corrosion inhibition of mild steel by ethylamino imidazoline derivative in $\mathrm{CO}_{2}$-saturated solution, Corros. Sci., 2009, 51, no. 4, 761768.

3. L. Herrag, B. Hammouti, S. Elkadiri, A. Aounitia, C. Jamab, H. Vezinc and F. Bentissd, Adsorption properties and inhibition of mild steel corrosion in hydrochloric solution by some newly synthesized diamine derivatives: experimental and theoretical investigations, Corros. Sci., 2010, 52, no. 9, 3042-3051. doi: 10.1016/j.corsci.2010.05.024

4. S. Cheng, S. Chen, T. Liu, X. Chang and Y. Yin, Carboxymethylchitosan $+\mathrm{Cu}^{2+}$ mixture as an inhibitor used for mild steel in $1 \mathrm{M} \mathrm{HCl}$, Electrochim. Acta, 2007, 52, no. $19,5932-5938$.

5. L.R. Chauhan and G. Gunasekaran, Corrosion inhibition of mild steel by plant extract in dilute $\mathrm{HCl}$ medium, Corros. Sci., 2007, 49, no. 3, 1143-1161. doi: 10.1016/j.corsci.2006.08.012

6. E. Bayol, T. Gürten, A.A. Gürten and M. Erbil, Interactions of some Schiff base compounds with mild steel surface in hydrochloric acid solution, Mater. Chem. Phys., 2008, 112, no. 2, 624-630. doi: 10.1016/j.matchemphys.2008.06.012

7. P.C. Okafor and Y. Zheng, Synergistic inhibition behaviour of methylbenzyl quaternary imidazoline derivative and iodide ions on mild steel in $\mathrm{H}_{2} \mathrm{SO}_{4}$ solutions, Corros. Sci., 2009, 51, no. 4, 850-859. doi: 10.1016/j.corsci.2009.01.027

8. E. Yousif, Y.F. Win, A.H. Al-Hamadani, A.A. Al-Amiery, A.A.H. Kadhum and A.B. Mohamad, Furosemide as an environmental-friendly inhibitor of corrosion of zinc metal in acid medium: Experimental and theoretical studies, Int. J. Electrochem. Sci., 2015, 10, no. 2, 1708-1715.

9. H.R. Obayes, G.H. Alwan, A.H.MJ. Alobaidy, A.A. Al-Amiery, A.A.H. Kadhum and A.B. Mohamad, Quantum chemical assessment of benzimidazole derivatives as corrosion inhibitors, Chem. Cent. J., 2014, 8, no. 21, 1-8. doi: 10.1186/1752-153X-8-21

10. A. Alobaidy, A.A.H. Kadhum, S. Al-Baghdadi, A.A. Al-Amiery, A. Kadhum and E. Yousif, Eco-friendly corrosion inhibitor: experimental studies on the corrosion 
inhibition performance of creatinine for mild steel in $\mathrm{HCl}$ complemented with quantum chemical calculations, Int. J. Electrochem. Sci., 2015, 10, no. 1, 3961-3972.

11. T.A. Salman, D.S. Zinad, S.H. Jaber, M. Shayaa, A. Mahal, M.S. Takriff and A.A. Al-Amiery, Effect of 1,3,4-Thiadiazole scaffold on the corrosion inhibition of mild steel in acidic medium: an experimental and computational study, J. Bio Tribo-Corros., 2019, 5, no. 48, 1-11. doi: 10.1007/s40735-019-0243-7

12. A.A. Al-Amiery, Y.K. Al-Majedy, A.A.H. Kadhum and A.B. Mohamad, New coumarin derivative as an eco-friendly inhibitor of corrosion of mild steel in acid medium, Molecules, 2015, 20, no. 1, 366-383. doi: 10.3390/molecules20010366

13. A.A. Al-Amiery, A.A.H. Kadhum, A.B. Mohamad and S. Junaedi, A novel hydrazinecarbothioamide as a potential corrosion inhibitor for mild steel in $\mathrm{HCl}$, Materials, 2013, 6, no. 4, 1420-1431. doi: $\underline{10.3390 / \mathrm{ma6041420}}$

14. A. Kadhim, E.T. Salim, S.M. Fayadh, A.A. Al-Amiery, A.A.H. Kadhum and A.B. Mohamad, Effect of Multipath Laser Shock Processing on Microhardness, Surface Roughness and Wear Resistance of 2024-T3 Al Alloy, Sci. World J., 2014, 1-6. doi: $\underline{10.1155 / 2014 / 490951}$

15. H.J. Habeeb, H.M. Luaibi, T.A. Abdullah, R.M. Dakhil, A.A.H. Kadhum and A.A. Al-Amiery, Case study on thermal impact of novel corrosion inhibitor on mild steel, Case Stud. Therm. Eng., 2018, 12, 64-68. doi: 10.1016/j.csite.2018.03.005

16. S.S. Al-Taweel, K.W.S. Al-Janabi, H.M. Luaibi, A.A. Al-Amiery and T.S. Gaaz, Evaluation and characterization of the symbiotic effect of benzylidene derivative with titanium dioxide nanoparticles on the inhibition of the chemical corrosion of mild steel, Int. J. Corros. Scale Inhib., 2019, 8, no. 4, 1149-1169. doi: 10.17675/2305-6894-2019$\underline{8-4-21}$

17. D. Mahmood, A.K. Al-Okbi, M.M. Hanon, K.S. Rida, A.F. Alkaim, A.A. Al-Amiery, A. Kadhum and A.A.H. Kadhum, Carbethoxythiazole corrosion inhibitor: as an experimentally model and DFT theory, J. Eng. Appl. Sci., 2018, 13, no. 11, 3952-3959.

18. H.R. Obayes, A.A. Al-Amiery, G.H. Alwan, T.A. Abdullah, A.A.H. Kadhum and A.B. Mohamad, Sulphonamides as corrosion inhibitor: experimental and DFT studies, J. Mol. Struct., 2017, 1138, 27-34. doi: 10.1016/j.molstruc.2017.02.100

19. D.M. Jamil, A.K. Al-Okbi, S.B. Al-Baghdadi, A.A. Al-Amiery, A. Kadhim and T.S. Gaaz, A.A.H. Kadhum and A.B. Mohamad, Experimental and theoretical studies of Schiff bases as corrosion inhibitors, Chem. Cent. J., 2018, 12, no. 7, 1-7. doi: 10.1186/s13065-018-0376-7

20. K. Al-Azawi, S. Al-Baghdadi, A. Mohamed, A.A. Al-Amiery, T.K. Abed, S.A. Mohammed, A.A.H. Kadhum and A.B. Mohamad, Synthesis, inhibition effects and quantum chemical studies of a novel coumarin derivative on the corrosion of mild steel in a hydrochloric acid solution, Chem. Cent. J., 2016, 10, no. 23, doi: 10.1186/s13065$\underline{016-0170-3}$ 
21. T.A. Salman, Q.A. Jawad, M.A.M. Hussain, A.A. Al-Amiery, L.M. Shaker, A.H. Kadhum and M.S. Takriff, New environmental friendly corrosion inhibitor of mild steel in hydrochloric acid solution: Adsorption and thermal studies, Cogent Engineering, 2020, 7, no. 1, 1-17. doi: $\frac{10.1080 / 23311916.2020 .1826077}{\text { A. Kadihum, A.H. Kadhum }}$

22. S. Junaedi, A.A. Al-Amiery, A. Kadihum, A.A.H. Kadhum and A.B. Mohamad, Inhibition Effects of a Synthesized Novel 4-Aminoantipyrine Derivative on the Corrosion of Mild Steel in Hydrochloric Acid Solution together with Quantum Chemical Studies, Int. J. Mol. Sci., 2013, 14, no. 6, 11915-11928. doi: 10.3390/ijms140611915

23. S.B. Al-Baghdadi, F.T.M. Noori, W.K. Ahmed and A.A. Al-Amiery, Thiadiazole as a potential corrosion inhibitor for mild steel in $1 \mathrm{M} \mathrm{HCl}, J$. Adv. Electrochem., 2016, 2, no. $1,67-69$.

24. M.H.O. Ahmed, A.A. Al-Amiery, Y.K. Al-Majedy, A.A.H. Kadhum, A.B. Mohamad and T.S. Gaaz, Synthesis and characterization of a novel organic corrosion inhibitor for mild steel in $1 \mathrm{M}$ hydrochloric acid, Results Phys., 2018, 8, 728-733. doi: 10.1016/j.rinp.2017.12.039

25. T. Koopmans, Über die Zuordnung von Wellenfunktionen und Eigenwerten zu den Einzelnen Elektronen Eines Atoms, Physica, 1933, 1, 104-113. doi: 10.1016/S00318914(34)90011-2

26. ASTM Standard Practices for Laboratory Immersion Corrosion Testing of Metals, American society for testing and materials G31-72, ASTM International, 2004.

27. S.B. Al-Baghdadi, F.G. Hashim, A.Q. Salam, T.K. Abed, T.S. Gaaz, A.A. Al-Amiery, A.A.H. Kadhum, K.S. Reda and W.K. Ahmed, Synthesis and corrosion inhibition application of NATN on mild steel surface in acidic media complemented with DFT studies, Results Phys., 2018, 8, 1178-1184. doi: 10.1016/j.rinp.2018.02.007

28. A.A. Al-Amiery, A.A.H. Kadhum, A.B. Mohamad, A.Y. Musa and C.J. Li, Electrochemical study on newly synthesized chlorocurcumin as an inhibitor for mild steel corrosion in hydrochloric acid, Materials, 2013, 6, no. 12, 5466-5477. doi: $10.3390 / \mathrm{ma} 6125466$

29. A. Kadhim, A.A. Al-Amiery, R. Alazawi, M.K.S. Al-Ghezi and R.H. Abass, Corrosion inhibitors. A review, Int. J. Corros. Scale Inhib., 2021, 10, no. 1, 54-67. doi: 10.17675/2305-6894-2021-10-1-3

30. M. Hanoon, D.S. Zinad, A.M. Resen and A.A. Al-Amiery, Gravimetrical and surface morphology studies of corrosion inhibition effects of a 4-aminoantipyrine derivative on mild steel in a corrosive solution, Int. J. Corros. Scale Inhib., 2020, 9, no. 3, 953-966. doi: $10.17675 / 2305-6894-2020-9-3-10$

31. S.B. Al-Baghdadi, A. Kadhim, G. Sulaiman, A.A. Al-Amiery, A.H. Kadhum and M.S. Takriff, Anticorrosion and antibacterial effects of new Schiff base derived from hydrazine, J. Phys.: Conf. Ser., 2021, 1795. doi: 10.1088/1742-6596/1795/1/012021 
32. A. Kadhim, G. Sulaiman, A.E. Abdel Moneim, R.M. Yusop and A. Al-Amiery, Synthesis and characterization of triazol derivative as new corrosion inhibitor for mild steel in $1 \mathrm{M} \mathrm{HCl}$ solution complemented with antibacterial studies, J. Phys.: Conf. Ser., 2021, 1795. doi: $10.1088 / 1742-6596 / 1795 / 1 / 012011$

33. M.M. Hanoon, A.M. Resen, A.A. Al-Amiery, A.A.H. Kadhum and M.S. Takriff, Theoretical and Experimental Studies on the Corrosion Inhibition Potentials of 2-((6Methyl-2-Ketoquinolin-3-yl)Methylene) Hydrazinecarbothioamide for Mild Steel in $1 \mathrm{M} \mathrm{HCl}$, Prog. Color, Color. Coat., 2022, 15, 11-23.

34. D.S. Zinad, R.D. Salim, N. Betti, L.M. Shaker and A.A. AL-Amiery, Comparative Investigations of the Corrosion Inhibition Efficiency of a 1-phenyl-2-(1phenylethylidene)hydrazine and its Analog Against Mild Steel Corrosion in Hydrochloric Acid Solution, Prog. Color, Color. Coat., 2022, 15, no. 1, 53-63.

35. R.D. Salim, N. Betti, M. Hanoon and A.A. Al-Amiery, 2-(2,4-Dimethoxybenzylidene)N-Phenylhydrazinecarbothioamide as an Efficient Corrosion Inhibitor for Mild Steel in Acidic Environment, Prog. Color, Color. Coat., 2022, 15, 45-52.

36. A.J.M. Eltmimi, A. Alamiery, A.J. Allami, R.M. Yusop, A.H. Kadhum and T. Allami, Inhibitive effects of a novel efficient Schiff base on mild steel in hydrochloric acid environment, Int. J. Corros. Scale Inhib., 2021, 10, no. 2, 634-648. doi: 10.17675/23056894-2021-10-2-10

37. A. Alamiery, E. Mahmoudi and T. Allami, Corrosion inhibition of low-carbon steel in hydrochloric acid environment using a Schiff base derived from pyrrole: gravimetric and computational studies, Int. J. Corros. Scale Inhib., 2021, 10, no. 2, 749-765. doi: 10.17675/2305-6894-2021-10-2-17

38. B. Xu, W. Yang, Y. Liu, X. Yin, W. Gong and Y. Chen, Experimental and theoretical evaluation of two pyridinecarboxaldehyde thiosemicarbazone compounds as corrosion inhibitors for mild steel in hydrochloric acid solution, Corros. Sci., 2014, 78, 260-268. doi: $10.1016 /$ j.corsci.2013.10.007

39. I. Obot, N. Obi-Egbedi and S. Umoren, Adsorption characteristics and corrosion inhibitive properties of clotrimazole for aluminium corrosion in hydrochloric acid, Int. J. Electrochem. Sci., 2009, 4, no. 6, 863-877.

40. M.H. Sliem, N.M. El-Basiony, E.G. Zaki, M.A. Sharaf and A.M. Abdullah, Corrosion inhibition of mild steel in sulfuric acid by a newly synthesized Schiff base: an Electrochemical, DFT and Monte Carlo simulation study, Electroanalysis, 2020, 32, no. 12, 3145-3158. doi: 10.1002/elan.202060461

41. A.A. Al-Amiery, A.A.H. Kadhum, A. Kadihum, A.B. Mohamad, C.K. How and S. Junaedi, Inhibition of mild steel corrosion in sulfuric acid solution by new Schiff base, Materials, 2014, 7, no. 2, 787-804. doi: 10.3390/ma7020787

42. A.B. Mohamad, A.A.H. Kadhum, A.A. Al-Amiery, L.C. Ying and A.Y. Musa, Synergistic of a coumarin derivative with potassium iodide on the corrosion inhibition of aluminum alloy in $1.0 \mathrm{M} \mathrm{H}_{2} \mathrm{SO}_{4}$, Met. Mater. Int., 2014, 20, 459-467. doi: $\underline{10.1007 / \mathrm{s} 12540-014-3008-3}$ 
43. M.H.O. Ahmed, A.A. Al-Amiery, Y.K. Al-Majedy, A.A.H. Kadhum, A.B. Mohamad and T.S. Gaaz, Synthesis and characterization of a novel organic corrosion inhibitor for mild steel in $1 \mathrm{M}$ hydrochloric acid, Results Phys., 2018, 8, 728-733. doi: $\underline{10.1016 / j . r i n p .2017 .12 .039}$

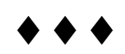

